\title{
EDUCAÇÃO MORAL E CÍVICA E ENSINO DE HISTÓRIA, APORTES DISCIPLINARES DE FORMAÇÃO: UM ESTUDO COMPARADO
}

\author{
Elaine Rodrigues* \\ Universidade Estadual de Maringá - UEM \\ Geraldo Inácio Filho \\ Universidade Federal de Uberlândia - UFU
}

\section{RESUMO}

Nosso objetivo foi desenvolver uma escrita comparada acerca da problemática que envolve o ensino de História no Paraná, registrando a identificação de uma continuidade em seus conteúdos, ainda que houvesse a proposição de uma ruptura. A problematização situou o tema em dois momentos representativos da História do Brasil. O primeiro período, ditatorial, é apresentado por meio dos objetivos da disciplina Educação Moral e Cívica. O segundo, pós-abertura política, é caracterizado por uma democracia (re)nascente e é apresentado por meio da análise do Projeto Pedagógico para o ensino de história destacando as expectativas democratizantes nele depositadas. Elegemos como fontes o Jornal da Educação, o Decreto-lei de criação da disciplina Educação Moral e Cívica, o Projeto Pedagógico para o ensino de história que é parte integrante do Currículo Básico para a escola pública no Paraná.

Palavras-chave: Educação comparada, Ensino de história, Educação moral e cívica, Democracia

\section{CIVIC AND MORAL EDUCATION AND THE TEACHING OF HISTORY, SOME CONTRIBUTIONS OF DISCIPLINARY TRAINING: A COMPARATIVE STUDY}

\begin{abstract}
Our aim was the development of a written comparison concerning the problems involved in the education of History in Parana. It was possible to register the identification of a kind of continuity in their content, although there were proposals for a disruption. The problematization placed the theme into two representative moments in the history of Brazil. The first period, dictatorial, is presented by the objectives of the discipline Civic and Moral Education. The second, post-political openness has the characteristics of a restarting and it is presented by means of pedagogical analysis about the projects for the teaching of History and it highlights the democratizing expectations placed on them. We have chosen as sources the Journal of Education, the Decree-Law creating the subject Civic and Moral Education, the Pedagogical Project for the teaching of History that forms part of the Basic Curriculum to the public school in Paraná.

Keywords: Comparative education, teaching History, Moral and Civic education, Democracy
\end{abstract}




\section{Disciplinas escolares: aportes do bem educar}

O que é educar? Pergunta célebre ao educador de e em formação e considerada clássica pelos os autores da década de 1980. Um texto bastante popularizado e escrito na referida década, traz o título, "O que é educação?", nele Brandão (1984, p. 10) conceitua educar como o moldar do sujeito dentro de uma cultura, o que acontece inicialmente no ambiente familiar, "[...] primeiro sem classes de alunos, sem livros e sem professores especialistas; mais adiante com escolas, salas, professores e métodos pedagógicos".

Educar pode, ainda, ser definido como uma ação naturalizada entre os sujeitos sobre seus pares e constitui-se como uma extensão dos indivíduos ou de um determinado grupo, com o objetivo de transmitir hábitos e costumes que preservem a identidade social (CHARTIER, 1990) que os mantém "iguais" socialmente, sem a utilização de técnicas pedagógicas escolares.

A educação escolar é intencional, uma obviedade que se torna de afirmação necessária para podermos nos apropriar da afirmativa do antropólogo, Larraia (2007), que defende serem os conteúdos escolares reveladores de uma seleção de conhecimentos em que a "unidade biológica" da espécie humana, em sua diversidade, deve adquirir. A máxima iluminista, a educação é o meio pelo qual o homem se torna homem, foi amplamente divulgada entre os educadores da década de 1980, e amparou Brandão (1984, p. 12) a fazer a seguinte ressalva, "[...] na prática, a mesma educação que ensina pode deseducar, e pode correr o risco de fazer o contrário do que pensa que faz, ou do que inventa que pode fazer". A educação escolar assume uma forma prescritiva, denominada disciplina ou matéria escolar, com o objetivo de legitimar ações, comportamentos, discursos formalizados, de não permitir um possível "deseducar" do sujeito.

Diretamente ligado ao campo educacional escolar, o francês Chervel (1990) escreve que, no século XIX, o termo disciplina ficou banalizado e acabou assumindo quatro formas de definições. A primeira designava vigilância, a segunda ginástica intelectual, na terceira a noção de disciplina passou do geral para o particular e na quarta o termo "disciplina" ficou designado como sendo genérico. $\mathrm{O}$ autor explica que em alguns lugares do mundo o termo disciplina reduziu-se a "metodologia" e o pedagogo, encarregado com sua pedagogia de lubrificar a "máquina escolar" e fazê-la girar. Segundo Chervel (1990), a disciplina escolar tem que ser reconhecida de um modo mais amplo, e não abrangendo nada mais do que práticas docentes da aula, mas com as grandes finalidades que presidiram sua constituição e o fenômeno de aculturação de massa que ela determina.

Chervel (1990) lembra que as disciplinas são o preço que a sociedade deve pagar a sua cultura, letrada, para poder transmiti-la no contexto escolar. Bittencourt (2004, p. 47) afirma que a "disciplina ou matéria escolar visa formar um cidadão comum que necessita de ferramentas intelectuais variadas para situar-se na sociedade e compreender o mundo físico e social em que vive".

É oportuno salientar que, em nenhum momento, Chervel (1990) desconsidera que as instituições escolares não estão totalmente livres dos mecanismos que forjam a reprodução de conhecimentos. Para este intelectual, enquanto o sistema educacional recusarse a compreender as especificidades que compõe as disciplinas, os historiadores devem olhar este sistema, como uma instância que apenas "[...] recebe e põe em contato dois tipos de população e de acordo com tal política educacional ou tal orientação pedagógica, ele ensina um certo número de matérias da qual a natureza não é de modo algum problemática" (CHERVEL, 1990, p. 183). Adverte-nos ainda, se a "escola for mesmo reprodutora de 
saberes, deve ser tratada como uma vulgarizadora das ciências, mas se a escola for criadora", esta instância merece ser estudada, conforme acredita Chervel (1990, p. 181).

Evidências empíricas ao alcance de pais, professores e alunos mostram que a escola está "esperneando" para, ao menos, manter-se em diálogo com a sociedade. O discurso articulado como tentativa de estímulo à mudança desse quadro apresenta sentenças afirmativas que remetem o professor a um fazer pedagógico que tenha como proposta educacional atingir o desenvolvimento integral e harmonioso de todas as capacidades do indivíduo. Paradoxalmente, a prática educativa tem se mantido, desde a modernidade, como um processo de adestramento seletivo da "formação de si". Lembrando-me de Nietzsche (1991), educar tem sido sinônimo de tornar o cidadão dócil, frágil e obediente aos valores em curso. Adestrar significa formar o indivíduo para obedecer a regras e incorporar novos hábitos; então, qual o papel da boa escola?

Diante do princípio de que educar tem sido adestrar, o papel de uma boa escola seria moldar o estudante, adequando-o, conformando-o como agente articulador em sua sociedade e cultura. Tomando por princípio essa vertente analítica, a educação tende a criar o homem teórico como modelo do resultado das práticas educacionais, de um ideal de educação, de uma ilusão constituída sob o pretexto de formação crítica. Mas, uma nova educação deve contemplar a formação de novos hábitos? Isto significaria construir uma nova natureza? Pressupõe-se que durante o processo educacional o aluno consiga desfazerse de sua primeira natureza? Deve abandonar os hábitos antigos de pensar e de ser? O que caracteriza o homem adestrado, na sociedade da velocidade?

Enquanto no panorama geral as discussões em torno da educação versam sobre temas de ordem filosófica, histórica, sociológica, em sala de aula o dilema do professor resume-se em manter a "disciplina", isso porque a escola não tem sido lugar de desafio, de produção do conhecimento, o que obriga o professor a trabalhar impondo a ditadura da ordem e a disciplina do silêncio. Para Barreiro (1998), a tarefa de ensinar acaba implicando, ainda que paradoxalmente, a destruição da liberdade. Afinal, qual é a liberdade possível?

Não sei se posso responder a contento, nosso inclusive, às questões que formulamos, porque não depende apenas de um maior número de leituras e de relações entre os estudos realizados, nem tampouco da nossa capacidade individual ou de outrem de assumir esta ou aquela postura teórico-metodológica ou de abarcá-las, mesmo que insatisfatoriamente. Segundo entendemos, isso se faz possível inserindo-nos no debate sobre a formação do educando, sobre o ato de ensinar. Mas ensinar o quê? E a quem? Buscaremos fazer isso circunscrevendo nossa problemática às últimas décadas do século $\mathrm{XX}$.

As últimas décadas do século $\mathrm{XX}$ apresentam duas posturas com relação ao ensino de História e seus conteúdos, dois momentos representativos da História da educação no Brasil. O primeiro, denominado período ditatorial, é apresentado neste estudo por meio dos objetivos da disciplina Educação Moral e Cívica. Faz-se necessário registrar, o entendemos como esclarecedores dessa temática, por denotarem o grau de confiança, de poder atribuído ao ensino de História, embora sua nomenclatura seja retirada oficialmente dos currículos, durante. Aparentemente a disciplina de Educação Moral e Cívica representa uma ruptura com a forma da disciplina e com os conteúdos anteriormente ensinados. Discordamos dessa tese, pois seus ensinamentos, portadores de forte carga ideológica, caracterizaram-se por permitir a formação de um homem pacífico, moralmente correto, patriota, um cidadão súdito.

Para encerrar esta brevíssima introdução, recordamo-nos do que Diderot d'Alembert (1978 apud MANACORDA, 1989, p. 241) já afirmava na Enciclopédia: 
Aquele que sabe somente a geometria intelectual é normalmente um homem sem destreza, é um artesão que tem somente a geometria experimental é um operário muito limitado [...] sobre certos problemas tenho certeza que é impossível conseguir algo satisfatório das duas geometrias em separado [...].

\section{O ensino de educação moral e cívica e a formação do patriota - $O$ ensino de história e a educação do homem crítico}

O espírito cívico, imposto pelo Decreto-lei $\mathrm{n}^{\circ} 869$, de 12 de setembro de 1969, visava à inclusão de Moral e Cívica como disciplina obrigatória nas escolas de todos os graus e modalidades dos sistemas de ensino no país. A intenção era inserir suas finalidades em todas as atividades escolares, inclusive no que diz respeito ao desenvolvimento dos atos cívicos, valorizados na prática educativa. As relações entre os valores humanos considerados superiores e a educação permitiriam que os cidadãos fossem integrados na sociedade, dela participantes como produtos culturais, como ilustrações no culto à nação, na identificação com a família e na dignidade do trabalho. A educação moral e cívica permaneceu no currículo oficial como disciplina escolar e prática educativa em todos os níveis de ensino por 24 anos, até 1993, quando foi revogada pela Lei ${ }^{\circ} 8.663$.

O propósito de inclusão da Educação Moral e Cívica seria, sinteticamente, a incorporação de seus ideais à sociedade, perpassando gerações, e isso deveria realizar-se como o próprio saber. A finalidade da Educação Moral e Cívica seria, preparar o homem para a vida, e, sobretudo, formar o cidadão para a sociedade, de acordo com as proposições do decreto que a criou. "Referir-se à formação do cidadão será admitir não ser possível realizá-la sem enfatizar a formação moral e cívica do educando para servir à sociedade e à família; sobressairão às atividades cívicas que - centradas no culto à nação têm origem na valorização do caráter nacional" (IBRASA, 1982, p. 43-44).

O segundo momento, configura-se como pós-abertura política, caracterizado por uma democracia (re)nascente, é demonstrado quando apresento o Projeto PolíticoPedagógico do Estado do Paraná e as expectativas que depositou no ensino de História. Analisando a proposta paranaense, que pretendia "repensar os conteúdos básicos das disciplinas no que se refere aos aspectos teórico-metodológicos de cada área de conhecimento" (PARANÁ, 1990, p. 13). O objetivo é refletir, comparativamente, sobre os questionamentos aqui sistematizados.

A qualidade do ensino, no início da década de 1980, entendia a Secretaria de Estado da Educação do Paraná, vinculava-se à possibilidade da não reprodução da sociedade injusta tal como se apresentava: de um lado os que sabiam, e por deterem o conhecimento detinham também o poder, e de outro os que não sabiam e obedeciam ao poder. A qualidade de ensino se vinculava à possibilidade de fazer com que a maioria da população pudesse dominar a soma de conhecimentos já acumulados através dos tempos, para que todos pudessem, juntos, se incumbir de criar uma nova sociedade.

$\mathrm{O}$ enfoque dado à questão da melhora na qualidade de ensino a ser oferecido pelo Estado estava no conteúdo a ser trabalhado. Uma proposta conteudista ${ }^{1}$ para a educação, que fixava suas bases naquilo que se ensinaria e não no como se ensinaria, tecendo críticas severas à visão tecnicista de educação e de ensino que era imperativa nos procedimentos didáticos de até então.

Aparentemente um novo e diferente olhar para a questão da qualidade de ensino "parecia" estar nascendo, pois se projetava em ações que exigiriam do educador assumir 
um compromisso político com a educação, por meio do ato de ensinar, e esses pressupostos se especificariam nos princípios por meio dos quais se ensinaria a História.

Conteúdos sociais, como o ato de a pessoa aprender a lutar por seus direitos, eram entendidos, pelos dirigentes educacionais, como uma nova postura social, que também deveria estar à frente dos projetos educacionais, o que imputava à problemática da qualidade de ensino a responsabilidade pela melhoria do panorama geral da educação paranaense.

A Secretaria de Educação do Estado do Paraná passa a editar o Jornal da Educação; fazendo valer o espaço de comunicação que esse folhetim significava, lança matérias para justificar o pedido de que novos comportamentos fossem assumidos, pelos professores, diante de "velhos" e enraizados costumes.

Quando se trata da questão do rompimento com determinadas posturas frente aos acontecimentos sociais, ou frente a determinadas propostas pedagógicas para se ensinar determinados conteúdos. Entendo ser importante nos reportarmos historicamente à razão para que determinadas atitudes ocorressem ou quais eram as finalidades disciplinares, e aqui nos interessa o ensino da História no contexto escolar. A História, como disciplina escolar, sempre trabalhou com as noções de "Identidade Nacional", "Cidadania", "Estado" e "Nação". Historicamente, o ensino de História foi marcado, em outros países e no Brasil, pelo ideal nacionalista.

O ideal nacionalista, sou redundante ao dizer, permeou o período militarista no Brasil. Alguns críticos ${ }^{2}$ da escola na década de 1980 evidenciavam o golpe militar de 1964 e sua correspondente ação relativa ao aspecto educacional como um marco. O conteúdo das ciências humanas, e particularmente o da História, havia se esvaziado de seu aspecto crítico. A crítica e a contestação, características inerentes ao ensino de História, haviam se perdido, e era manifesto o seu caráter de instrumento de veiculação e formação do espírito cívico, entendido como aquele capaz de glorificar os feitos dos auto proclamados heróis do dia. $^{3}$

Anteriormente a esse período, o que se acredita, portanto, é que teria existido um ensino de História diferente do apregoado pelas disciplinas de Organização Social e Política do Brasil e Educação Moral e Cívica, incluídas no currículo em substituição a ela. Da mesma forma, no período que se segue, momento de "abertura política no país", a crença é a de que a tarefa do educador seria romper com os ideais tradicionalmente presentes no ensino de História para construir uma escola democrática, uma escola que deixasse de formar o cidadão-súdito e passasse a construir um cidadão-participante. (LAVILLE, 1999).

Uma dessas situações esteve relacionada a um dos conteúdos do ensino de História: as comemorações cívicas ligadas ao dia sete de setembro. O dia da independência era tradicionalmente comemorado, no calendário escolar, com um "garboso" desfile, um culto à nação. Era um feito que se realizava para atender às expectativas de um projeto de ensino que visava à formação moral e cívica do educando, que compreendia a essência da nacionalidade, sintetizada em armas, brasões e símbolos, denotando as aspirações, militares, para a construção da nação brasileira com ordem, progresso e igualdade entre os homens. (FERRARINI, 1979).

Se um decreto-lei inseriu na escola conteúdos de moral e de civismo, caracterizando um ato de determinação hierarquicamente superior e inquestionável, no ano de 1983, em pleno processo de abertura política e finalização do regime militar, os professores, mais uma vez por determinação superior, são avisados de que não mais seria necessário que o ato cívico acontecesse. 
A Secretaria de Educação "sugeria" que as comemorações se dessem no interior da escola. Sobre as comemorações afetas à Semana da Pátria, as diretrizes propunham que esse momento passasse a ser considerado como um momento de reflexão em torno da questão da cidadania. $\mathrm{O}$ ato cívico do sete de setembro passaria a ter características reflexivas que partiam do pressuposto de que a ação pedagógica deveria se dar aliada ao compromisso político do cidadão para com a nação.

Dentro do ideal democrático assumido e professado pela SEED - Secretaria de Estado da Educação, no seu Projeto Pedagógico, todos os envolvidos no fazer educacional seriam responsáveis politicamente pela formação do cidadão, entendido como um ser capaz de, conscientemente, responder pelos seus atos (PARANÁ, 1983).

Não mais se admitia, segundo os princípios da SEED, que os participantes das comemorações falassem sobre as atividades que tivessem desenvolvido como se fossem alheios aos fatos, comportando-se como expectadores passivos no processo. $\mathrm{O}$ ato de questionar, de emitir opiniões não era habitual no projeto político em que o professor estava, por costume, inserido. O ser civicamente instruído era um agente passivo, pois a passividade havia sido estimulada durante os anos de militarismo como uma virtude. $\mathrm{O}$ cidadão, passivo ou ativo, continuava sendo requisitado como conformador de um ideal para a nação. Um ideal que culturalmente continuava a forjar heróis nacionais.

A Secretaria de Educação do Paraná, por meio do seu Projeto Político-Pedagógico, pedia uma participação consciente, livre, crítica e profunda, que fosse capaz de despertar professores, alunos e a comunidade para pensar e agir sobre a realidade. A passividade diante dos fatos representava um problema a ser discutido. Porém, a maior dificuldade para se conseguir desenvolver um projeto educacional que primasse pelo ensino de boa qualidade derivava, de acordo com a opinião dos dirigentes educacionais, precisamente da falta de uma metodologia, e das respectivas práticas elaboradas para essa tarefa.

O ensino de História ganha especial destaque na proposta da SEED, e isso se deu por ter sido despertado, por intermédio dos conteúdos de Educação Moral e Cívica que se veiculava nas escolas, o ideal nacionalista militar. O que se pretendia nos idos de 1980, em contraposição ao nacionalismo moralizante, é que o ensino de História fosse um aliado consciente do compromisso político do professor, que socialmente deveria objetivar com o ato educativo a "igualdade entre os homens".

$\mathrm{O}$ ato educativo objetivava igualizar os homens em todos os níveis, de modo que não houvesse divisão social entre intelectuais e ignorantes. Dirigida a esse objetivo, a instrução alteraria a constituição da sociedade, tornando-se um elemento político de mudança. A perspectiva educacional que objetivava a igualdade de todos os cidadãos exigia que diferentes formas e estímulos fossem encaminhados para instruir aqueles que já tinham sido prejudicados pelo sistema econômico e político. Parecia ser lógico, aos dirigentes educacionais, que essa opção levaria a uma melhor qualidade de ensino, a qual não se restringia à exigência de fornecer a todo e qualquer usuário da educação o mesmo conjunto de conhecimentos. Essa opção exigia, ainda segundo seus idealizadores, a não simplificação ou o não barateamento dos conteúdos ministrados nas instituições escolares aos alunos das classes populares.

O ideal de cumprir esses objetivos não poderia prescindir de uma formulação adequada das atividades escolares. O discurso da SEED anunciava-se comprometido com os que necessitavam aprender. Declarava crer que a vida escolar deveria ser organizada em torno das atividades dos alunos, e pedia que o ambiente da escola oferecesse a maior variedade possível de situações produtoras de ensino. Pressupunha que a pessoa se apropria dos saberes por força da própria atividade, e não segundo a concepção de modelos e programas pré-fixados. 
Tal discurso convidava o professor a participar da construção da prática escolar, partilhando com os demais interessados a premissa de que

Importa todo o universo de conhecimentos, já acumulados e sistematizados pela humanidade. Mas muito mais importa que o aprendiz incorpore o conhecimento das regras de funcionamento da sociedade, sua origem, formação e reprodução. Importa também trabalhar um novo perfil do educador que leve em conta: a capacidade de trabalhar politicamente com outros educadores e animadores sociais; a visão pedagógica global e não somente de especialista; a capacidade de construir o ensino com os aprendizes, excluindo toda forma de condicionamento e dependência. Um educador crente e esperançoso numa sociedade de relações equânimes, construtor da educação como prática social, hábil em produzir ciência comprometida com o ganho cumulativo de vida e liberdade (PARANÁ, 1985, p. 12).

Os conteúdos pretendidos, propostos pela Secretaria de Estado da Educação para o ensino de História, acabam por ser sistematizados na formulação do Currículo Básico do Paraná e de materiais didáticos como os cadernos intitulados Lições do Professor, que pretendiam deixar claro que a proposta de trabalho compreendia que a História poderia ser apreendida em três dimensões (PARANÁ, 1990):

A História vivida: aquela que é vivida por nós, no presente e foi vivida por todos os homens no passado (organizados em classes, grupos e em sociedade). Essa História é objeto de estudo dos historiadores. A História produto da reflexão dos pesquisadores, estudiosos. É o conhecimento histórico acumulado - a historiografia. A História como matéria de ensino, isto é, o conteúdo que já foi selecionado do conjunto histórico produzido e que foi sistematizado para ser ensinado nas escolas. Nós, professores, ao trabalharmos com os nossos alunos, devemos ter consciência da necessidade da relação entre estas três dimensões: relacionando o conteúdo que estamos ensinando com a produção historiográfica mais avançada e ao mesmo tempo com a História que vivemos e com uma proposta de ensino de História (PARANÁ, 1990).

A Secretaria de Educação defendia, insistentemente, a obrigatoriedade de o professor priorizar, em suas ações pedagógicas, seu compromisso político, imprimindo uma diretriz ao seu fazer pedagógico. Essa postura, de certa forma imposta ao professor, pretendia ser uma força iluminadora na atuação de todos os envolvidos com o cotidiano escolar.

O discurso da SEED alicerçava-se na premissa de que a educação estava sendo repensada e resgatada como um ato político, suas consequências sociais não poderiam deixar de ser consideradas. Afirmava que os resultados do ensino são resultados políticos, e que a atividade do professor, de ensinar na escola, necessitava ser realizada como um compromisso político com a sociedade. A ação educativa estava sendo discutida e determinada pela Secretaria, pressupondo-a como um ato político, porque sua prática tem consequências. "É um ato político porque orienta a ação humana, que é, e sempre foi, inspirada em opções políticas, filosóficas e ideológicas”. (PARANÁ, 1984, p. 4).

De maneira coerente com essa postura, tomada mediante $o$ ato de ensinar e suas consequências, a SEED define, assim me parece, pressupostos que intencionavam estimular o entendimento, pelo professor, do compromisso político que as atividades escolares por ele desenvolvidas significavam. Reiterava essa ideia em todos os espaços de comunicação, tal como a seguir: 
[...] como sabemos, a fonte de todos os tormentos na área educacional é essencialmente política e hoje situa-se no projeto político, de caráter nacional, responsável pela educação vigente no País. Resolver em profundidade os problemas candentes que a todos angustiam significa atacar a fonte primeira de sua ocorrência (PARANÁ, 1984, p. 3).

A disciplina de História fora resgatada, por esse projeto, como uma aliada. Recebeu destaque como detentora de saberes indispensáveis ao projeto político de sociedade que se formulava no período pós-ditadura militar. Caracterizá-la, a partir do projeto em análise, como uma solução milagrosa de libertação, seria um descuido analítico; entretanto, destacamos que se atribuía a ela a potencialidade da elevação direta do nível de consciência dos educandos. Por meio de seus conteúdos fazia-se possível que se tomasse contato com uma forma de pensamento esclarecedor com relação à classe social a que se pertencia, e de posse desses conhecimentos caberia ao educando interferir na sociedade, como sujeitos históricos, contribuindo para a sua transformação. Qualitativamente se estaria oportunizando o conhecimento de "níveis mais elaborados de abstração, o que é um dos requisitos para o exercício da cidadania” (PARANÁ, 1984, p. 10).

O discurso que embasa o Projeto Político-Pedagógico da SEED é coerente; entretanto, se isso for relacionado às ações concretas, efetivamente realizadas, essas são mais modestas do que as intenções anunciadas. O conteúdo das propostas veiculado nos documentos é bastante repetitivo, chegando a ser enfadonho.

Os argumentos propostos como estratégias reflexivas, objetivando a elevação do nível educacional, remetem o leitor a um raciocínio de caráter solidário; o pedido é de participação, comunhão, humildade, dedicação, responsabilidade. Essa é a tônica do discurso. O teor argumentativo do projeto, quando discute qualidade de ensino, é messiânico, como se, respondendo às expectativas da SEED, a população pudesse conquistar uma nova sociedade, mais justa, mais fraterna, mais livre, com níveis de consciência mais elaborados.

O Jornal da Educação, divulgador do projeto, apropria-se de textos como o de D. Helder Câmara, utilizando-os como reforço para o enfoque pretendido. Assim, publica-se:

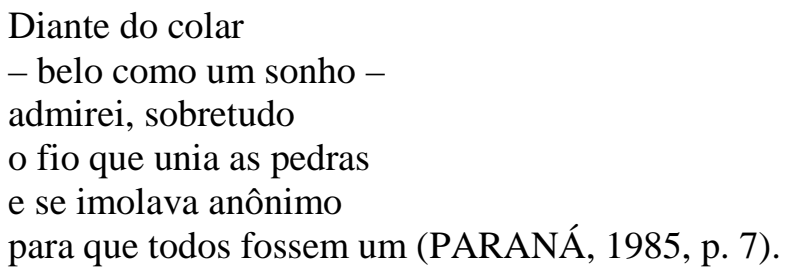

Dentro da mesma lógica, um discurso proferido por outro padre é tomado pelo jornal como parâmetro e levado até às escolas. Dessa vez a palavra de força é justiça, e neste contexto os problemas educacionais vão, pela imposição da linguagem, tomando contornos nos quais a busca de solução para os problemas educacionais parece ser possível, se efetivada como problema de fé. Esperava-se que o educador se posicionasse como uma pessoa presente na vida de seus alunos. Tal como numa profissão de fé, anunciava-se:

A educação para a justiça implica num compromisso com a construção de uma sociedade na qual "prevaleçam a participação e a comunhão [...] mas, se durante todo o processo de educação formal, a criança e o jovem são tratados como incapazes de decidir sobre as coisas que lhes dizem respeito, não estaremos preparando pessoas dispostas a buscar essa mesma participação e comunhão em sociedade" (PARANÁ, 185, p. 6). 
O sonho, algo tão particular, também foi resgatado de forma social, como argumento para reflexão sobre as questões educacionais. Se o homem estivesse completamente privado da capacidade de sonhar, se não pudesse de vez em quando adiantar-se a contemplar em sua imaginação o quadro inteiramente acabado da obra que esboça em suas mãos, não poderia imaginar o que o obrigaria a empreender e levar a termo, vastas e penosas empresas no terreno das artes, das ciências e da vida prática. $\mathrm{O}$ desacordo entre os sonhos e a realidade não produz dano algum, sempre que a pessoa que sonha creia sinceramente em seu sonho (PARANÁ, 1985).

Construir a realidade a partir de seus sonhos, crer sinceramente nos sonhos... As afirmações me levam a pensar que, durante o processo de administração, o entusiasmo e a crença na nascente democracia como solução para todos os problemas era uma premissa que começava a ficar nos sonhos; ou ainda, dito de outra forma, mantém-se como elemento do discurso. Mas, e a tão sonhada, decantada qualidade de ensino que figurou no discurso educacional dessa época como elemento transformador da sociedade? Continuou a figurar, não mais como poderes revolucionários, transformadores, mas como possibilidade de formação moral, de conduta ética. Reforçamos, com a própria trajetória do Projeto Pedagógico dos anos 80, a premissa de que não houve rompimento significativo na forma. E tampouco no conteúdo, com o que se ensinava em História: a busca continuou a ser moralizante e nacionalista.

A importância atribuída à disciplina de História, diante dos princípios humanistas e não mais políticos, foi estrategicamente substituída por uma súbita relevância dada à disciplina de desenho, por meio da qual se pretendia que o aluno, no conjunto das aquisições que a escola lhe proporcionava, pudesse interagir com o mundo, e não ser dominado por ele. Na perspectiva de uma atuação diferenciada do período ao qual se opunha, o ditatorial, a SEED ia criando ações em que o debate acerca de questões educacionais pudesse, segundo seu entendimento, melhorar o ensino, ainda que a saída estivesse na fé. O que se passa a procurar já não é a glória de um projeto que se opunha aos "famigerados" anos da ditadura militar, mas uma identidade.

$\mathrm{Na}$ busca por essa identidade o tema cidadania ocupa lugar de destaque, não somente nas discussões acadêmicas como também nos discursos políticos veiculados em defesa dos movimentos populares, tornando-se um dos conceitos mais utilizados à época. Nunca se falou tanto em cidadania!

A nossa Constituição, em seu Título VIII, capítulo III, traz um artigo que faz alusão à questão da cidadania, em seu art. 205, determinando que a "educação, direito de todos e dever do Estado e da família, será promovida e incentivada com a colaboração da sociedade, visando ao pleno desenvolvimento da pessoa, seu preparo para o exercício da cidadania e sua qualificação para o trabalho" (VITA, 1989, p. 182).

Os Parâmetros Curriculares Nacionais indicam, como um dos objetivos do ensino fundamental, que os alunos sejam capazes de

compreender a cidadania como participação social e política, assim como exercício de direito e deveres políticos, civis e sociais, adotando, no diaa-dia, atitudes de solidariedade, cooperação e repúdio às injustiças, respeitando o outro e exigindo para si o mesmo respeito; bem como, a necessidade de conhecerem as características fundamentais do Brasil nas dimensões sociais, materiais e culturais como meio para construir progressivamente a noção de identidade nacional (BRASIL, 1998, p. 7).

Diante de proposições e pareceres acerca do tema, é preciso que se alerte para o risco de sua excessiva utilização. Conceitos aplicados de forma indiscriminada sem que se 
considerem as circunstâncias culturais, políticas e históricas que o envolvem acabam por sofrer um esvaziamento em seu sentido. As noções de cidadania, democracia e política são conceitos/categorias que, por frequentarem assiduamente o discurso modernizante do século XX, assumiram significados, por vezes, com características excessivamente positivas. Quase como magia, esses termos se especificam no interior de projetos pedagógicos e contextos sociais diferentes. Classificamos, assim, o documento que se está analisando nesta perspectiva: a da quase "magia"!

A relação entre o discurso proferido e a ação efetivada não é simples. A prática efetiva está entrecortada por motivos conflitantes entre os personagens implícitos no discurso que fundamenta o projeto político. As políticas formuladas por um órgão oficial estatal e as publicações da SEED são repostas oficialmente dadas às demandas geradas por grupos, por facções da sociedade. O teor do discurso é esperado. O conteúdo é redigido para atender a demandas específicas. Essas necessidades podem ser gestadas por vários segmentos, mas o projeto atenderá a apenas um deles. A equipe da Secretaria de Educação privilegia um discurso que se propõe a optar pelas maiorias carentes, pelos excluídos.

A equipe pedagógica constituída pela SEED, após o regime militar, orientou-se, num primeiro momento, pelas denominadas pedagogias progressistas. Entretanto, na contramão do discurso as outras instâncias governamentais não se mantiveram em consonância com a Secretaria de Educação, ou seja, não houve o aparato necessário à manutenção dos compromissos assumidos em campanha; por exemplo, os professores tiveram seus salários arrochados. Com a sobrevivência ameaçada, como construir cidadania, como sentir-se, positivamente, participante de um projeto, quando se é a parte desfavorecida desse projeto?

Diante desses desafios o discurso toma nova formatação e se mistura a conteúdos de fé, trazendo à tona a velha ideia de que a profissão do educador se confunde com um sacerdócio; portanto pleno de resignação, determinação, humildade, com menos exigências, para ser exercido em prol do bem comum.

\section{Sobre semelhanças e diferenças}

Houve, na década de 1980, uma tentativa de descartar o componente conservador da Educação Moral e Cívica, incorporando nos programas de História uma perspectiva mais comprometida com a participação democrática, por meio de um discurso que pretendia trabalhar com conteúdos mais significativos à sociedade. Os significados são construídos, e essa significação não é desarticulada dos interesses que a compõem e propõem. A questão se coloca para além da intencionalidade grupal. Culturalmente somos frutos da mentalidade que engendrou os conteúdos de História, como matéria escolar, na formação dos educandos no final do século XIX, no Brasil, cujo objetivo à época era legitimar a formação da Nação. No final do século XX, novas demandas surgiram e a escola as atendeu formando o seu educando "criticamente", atitude que, mais uma vez, o fazia adequado.

Especificamente relacionada ao campo disciplinar da História, a proposta paranaense propunha-se desenvolver um trabalho em que ensinar História fosse sinônimo de educar para a cidadania democrática, tornando os jovens capazes de participar. Em consonância com o período anterior, e não rompendo com ele, mantém-se o ideal de conformação dos sujeitos à nação no estado em que se encontrava, legitimando a ordem social e política, fosse ela ditatorial ou democrática. Torna-se representativo destacar que, tomadas como referência quer a disciplina de História, quer a disciplina de Educação Moral e Cívica não são diferentes; existe um processo contínuo de conformação de seus 
conteúdos ao ideal de formação do cidadão. A seleção de conteúdos, nas duas disciplinas, prima pela manutenção da tradição do ensino nacionalista e patriótico, calcado na História da civilização ocidental e no modelo eurocêntrico. Ainda buscamos o herói! Sendo "conservador" ou "revolucionário", a ele compete à tarefa de redimir a sociedade de seus males.

A reestruturação do sistema brasileiro de proteção social esteve no centro dos discursos sobre possíveis reformas a serem executadas durante os anos 1980. Embora essa década nascesse com o sonho de uma sociedade democrática, ela morre em meio ao pesadelo de não ter realizado as promessas que a inauguraram. Essa constatação, frequentemente exposta aos olhos dos educadores, fez nascer um período de desencanto, contrariando a aposta na suposição de que o processo de democratização da escola aceleraria o caminho para a democratização da sociedade, com o consequente acesso à cidadania, o que não se efetivou, muito embora o discurso baseado nessa tese tenha se reconstituído durante as duas últimas décadas do século XX.

A instituição educativa não é um espaço neutro. Essa não é uma constatação nova. Seu espaço é disputado como palco para discursos ora de manutenção da ordem ora para sua mudança. Nesse contexto de disputa pelo poder político, a educação se manifesta como elemento catalisador. Entendê-la como aceleradora de um processo faz com que seja constantemente resgatada. Nessa lógica, os conteúdos pertinentes ao ensino de História durante as últimas décadas, na forma ditatorial ou na da democracia representativa, sempre atenderam ao ideal de nacionalidade.

O Estado, ao definir uma política educacional, percorre um longo processo de elaboração, até o fazer-se na prática educativa, nas unidades escolares. No caminho, o discurso por uma escola pública, gratuita, democrática e universal pode se manter, mas a prática que a efetivaria se segmenta nas esferas em que a educação se reproduz e se diferencia nas formas de apropriação desse discurso. (CHARTIER, 1990).

Não se pode desconsiderar, como elemento dificultador de uma prática educacional mais próxima das expectativas dos agentes nela envolvidos, a ação de uma política clientelista, que permeia a distribuição e a gestão dos recursos para a educação, em todos os seus níveis. Educa-se para atender a interesses. Educar é sempre criar adequação "a". Ou, dito de outra forma, é o aprendizado de um sistema de valores em curso, o que a nosso ver, o sistema de ensino brasileiro tem tentado realizar, qualquer que seja a forma política de configuração do Estado, ditatorial ou democrático.

Atualmente pede-se à escola e ao professor, que conceba seu fazer pedagógico com base na transmissão de valores, objetivando à inter e a transdiciplinaridade em seus currículos e programas. Aprender valores em curso pode ser definido como adestramento, formação do indivíduo para a obediência de regras e a incorporação de hábitos. Não é possível ser independente do mundo em que se vive. Somos o que conseguimos criar, inventar como sociedade. Não estamos fazendo apologia da condenação a uma forma de vida, como se ela fosse estagnada. Como nunca vivenciamos o mundo da velocidade, do movimento, não há espaços nem definições que possam dar conta do que se denomina atual. Existe o espaço tangencial, aquele que foge à lógica da ciência, à formação acadêmica, e o encontro desse espaço é que nos desafia como pesquisadores/professores/alunos.

A escola, a despeito de ter sido aclamada durante as décadas de 1980 e 1990 como uma possível redentora dos problemas sociais, definitivamente não o é. Em nossos dias ser detentor de saber sistematizado não garante a sobrevivência, o emprego, nem sequer a adequação dos indivíduos ao seu meio, o que me permite afirmar que o ensino de História tem ou teve pouquíssimas chances de exercer o poder que os vários projetos educacionais 
derivados de um único projeto de nação, o de criação de uma identidade nacional, lhe conferiram.

As entidades brasileiras, formalmente organizadas em prol de uma educação pública, universal, gratuita e de qualidade, reclamam insistentemente, junto aos seus governantes, uma ação que mantenha a oferta de educação para todos. Entra governo, sai governo e as promessas eleitoreiras não saem dos palanques. No caso das políticas educacionais, elas se definem como uma sofisticação dessas promessas.

Estamos no século XXI. O futuro chegou, e nossas reivindicações ainda passam por questões do início do século passado. Na entrada do período republicano no Brasil, José Veríssimo publicava a Educação Nacional (VERÍSSIMO, 1985) uma obra que estabelece, pela via educacional, três pilares para o desenvolvimento e progresso da nação brasileira. São eles: A Educação do Caráter, a Educação da Mulher e a História Pátria. Hoje, o discurso promovido pelos órgãos oficiais acerca da construção de uma sociedade democrática, mais cidadã, funda-se num apelo ao trabalho voluntário. O indivíduo é cada vez mais requisitado a prestar sua contribuição, e o discurso continua "seduzindo" pelo social. Projetos como "Amigos da Escola", "Acorda Brasil! Está na hora da escola!"4, figuraram nos anos de 1990, como "salvacionistas", seus argumentos ofertam possibilidades, das mais simples até as mais sofisticadas, e todas são bem recebidas. $\mathrm{O}$ discurso em prol da cidadania, com base na formação do cidadão, consciente de seus deveres, confiante em seus direitos, continua se ancorando num tom humanista e cristão, baseado na solidariedade.

A educação tem vivido "uma guerra atômica sem o átomo, mas análoga pelo impacto" (BAUDRILLARD, 1992, p. 89). Optamos por as reflexões fazendo algumas considerações acerca da problemática da conceitual da educação e da formalização dos conteúdos das disciplinas escolares, enfatizamos o caráter heterogêneo dessa sociedade e os efeitos que constatamos e entendemos como afetos à questão da velocidade. $\mathrm{O}$ caminho percorrido intentou demonstrar que é falaciosa a ideia de que está nas mãos dos educadores compromissados politicamente com sua nação a possibilidade de sua transformação, e de que o melhor ensino, ou o ensino de qualidade, seria aquele que aumenta e estimula a atividade do homem, que engendra a vida.

A crença em uma concepção teórica universal, totalizante, para se pensar, compreender e interferir na sociedade se revelou, ao longo do desenvolvimento do Projeto Político-Pedagógico proposto pela SEED, como um simulacro. Falou-se tanto em social que o social se perdeu no social. Tentou-se, por meio de uma concepção teóricometodológica imputar tudo ao social, exprimir todo o social, quis-se retirá-lo da dimensão representativa, e com isso ele se diluiu. Centrifugou-se. O ensino das disciplinas é mutável no tempo, seu exercício pedagógico também o é; seu conteúdo é que tem resistido a todas essas mutações, o que caracteriza as continuidades desse fazer.

\section{Referências}

BARREIRO, José Carlos. Os Parâmetros Curriculares Nacionais e os novos desafios da escola. In: HISTÓRIA E CIDADANIA; SIMPÓSIO NACIONAL DE HISTÓRIA, 19. ANPUH. 1998. p. 584.

BAUDRILLARD, Jean. A ilusão do fim ou a greve dos acontecimentos. Tradução de Manuela Torres. Lisboa: Ed. Terramar, 1992. 
BITTENCOURT, Circe Maria Fernandes. Ensino de História: fundamentos e métodos. São Paulo: Cortez, 2004.

BITTENCOURT, Circe Maria Fernandes. Propostas curriculares de história: continuidades e transformações. In: BARRETO, Elba Siqueira de Sá (Org.). Os Currículos do ensino fundamental para as escolas brasileiras. Campinas, SP: Autores Associados; 1998. p.127 - 163 (Coleção Formação de Professores).

BRANDÃO, Carlos Rodrigues. O que é educação? São Paulo: Brasiliense, 1984.

BRASIL. Secretaria de Educação Fundamental. Parâmetros Curriculares Nacionais: terceiro e quarto ciclos: apresentação dos temas transversais. Brasília, DF: MEC/SEF, 1998, p. 7.

CHARTIER, Roger. A história cultural: entre práticas e representações. Tradução de Maria Manuela Galhardo. Lisboa: Difel, 1990.

CHERVEL, André. História das disciplinas escolares: reflexões sobre um campo de pesquisa. Teoria \& Educação, Porto Alegre, n. 2, v.1, p. 177-229, 1999.

CNMC. (Conselho Nacional de Ministros e capelães). Educação Moral e Cívica. 1973. p. 5-7.

FERRARINI, Sebastião. Armas, brasões e símbolos nacionais. 1979. p. 15.

FOLDER DO BOLETIM Acorda Brasil, ano 1, n. 1, 1997.

IBRASA. O cidadão e o civismo. 1982. p. 43-44.

LARRAIA, Roque de Barros. Cultura: um conceito antropológico. Rio de Janeiro: Jorge Zahar, 2007.

LAVILLE, Christian. A guerra das narrativas: debates e ilusões em torno do ensino de História. Rev. bras. Hist., v. 19, n. 38, p. 125-138, 1999.

MANACORDA, Mario Alighiero. História da educação: da antiguidade aos nossos dias. São Paulo, Cortez, 1989.

NIETZSCHE, F. W. Obras incompletas: seleção de textos de Gerard Lebrun, tradução e notas de Rubens Rodrigues Torres. 5. ed. São Paulo: Nova Cultural, 1991. p. 114.

PARANÁ. Cadernos Lições do Professor, Curitiba: SEED, p. 91, 1991.

PARANÁ. Currículo Básico para a Escola Pública do Estado do Paraná. Curitiba: SEED, 1990.

PARANÁ. Fundamentos e explicitação das políticas da SEED. Curitiba: SEED, 1983. p. 5-9.

PARANÁ. Jornal da Educação, Curitiba: SEED, ano 2, n. 7, p. 3, nov./dez. 1984.

PARANÁ. Jornal da Educação, Curitiba: SEED, ano 3, n. 9, p. 12, mar./abr. 1985.

PARANÁ. Jornal da Educação, Curitiba: SEED, p. 4, mar./abr. 1984.

PARANÁ. Jornal de Educação, Curitiba: SEED, p. 7, jan. /fev. 1985.

VERISSIMO, José. A Educação nacional. 3. ed. Porto Alegre: Mercado Aberto, 1985.

VITA, Álvaro de. Nossa Constituição. São Paulo: Ática, 1989. 


\section{Notas:}

*Elaine Rodrigues é Professora Associada do Departamento de Fundamentos da Educação e do Programa de Pósgraduação em Educação da Universidade Estadual de Maringá (UEM). Maringá - Paraná - Brasil. e-mail: erodrigues@uem.br.

Geraldo Inácio Filho é professor titular da Universidade federal de Uberlândia e do Programa de Pós-graduação em Educação dessa mesma Instituição. Uberlândia - Minas Gerais - Brasil . e-mail: geraldoinacio@terra.com.br.

${ }^{1}$ A proposta foi desenvolvida, com rigor, pelo professor Dermeval Saviani em sua formulação sobre a educação, denominada: "Pedagogia Histórico-Crítica". Sobre essa temática ele publicou vários títulos, o mais famoso, Escola e Democracia, que no de 1986 já estava em sua 11 ${ }^{\text {a }}$ edição. Em entrevista concedida a APP sindicato, no ano de 1997, o próprio professor Dermeval Saviani alerta sobre os riscos de se fazer uma adesão pré-critica a novas propostas educativas. São suas palavras: "Quando eu lecionava na pósgraduação e discutia a adesão pré-crítica a teorias pedagógicas, eu discutia até os próprios conceitos que nós trabalhávamos. Por exemplo, a filosofia da educação como reflexão radical e rigorosa do conjunto de problemas que a educação apresenta [...] muitas vezes o aluno recitava isto, e fazia uma adesão pré-critica. Por isto e a partir daquelas razões que eu dei o nome de Pedagogia Histórico-crítica, também não esteve imune a isto. Isto ocorreu no Paraná [...] esta concepção foi implantada no Paraná, na tentativa de se formular algo consistente, e a forma como isto foi sucumbindo posteriormente. Ocorreu uma adesão précrítica e foi tratada como moda. Houve um momento em que ela se difundiu e adquiriu uma certa hegemonia, sendo então abraçada como moda [...] Hoje, às vezes, eu até digo: ainda bem que passou a moda (APP, 1987, p. 7-22).

${ }^{2}$ Neidson Rodrigues foi colaborador do Jornal da Educação editado pela SEED. Uma de suas matérias foi publicada no ano 2, n. 5, p. 6, jul./ago. 1984; publicou também Por uma nova escola: o transitório e o permanente na educação. São Paulo, Cortez, 1985 e ainda, Lições de Príncipe e outras lições. São Paulo: Cortez, 1987. Da mistificação da Escola a escola necessária. São Paulo: Cortez, 1987.

${ }^{3}$ Ernesta Zamboni discute essa questão no texto: Projeto pedagógico dos parâmetros curriculares nacionais: identidade nacional e consciência histórica. Caderno CEDE, v. 23, n. 61, dez. 2003. A autora também discorda da ideia de que tenha havido uma ruptura na forma e no conteúdo do ensino de História em relação ao período anterior a 1964 e em sua sequência após o Golpe de 1964.

${ }^{4}$ São projetos desenvolvidos pelo Governo Federal - MEC e abrangem todo o território nacional. O programa Amigos da Escola foi lançado no final dos anos de 1990, sendo o mais conhecido dos exemplos. Conta com o apoio da Rede Globo de Televisão. "Acorda, Brasil! Está na Hora da Escola! Foi criado em março de 1995: é um projeto que traz como slogan - "Brasil em ação" - como contribuir para melhorar a escola pública. Incentiva a sociedade a assumir sua parcela de responsabilidade em relação à qualidade da escola e da Educação. Esse projeto destaca, ainda: "cada um de nós pode fazer muito pela escola, seja enquanto profissional ou na condição de pais, avós, tios, etc. Fica mais claro a cada dia que as soluções dependem da ação de todos. O Acorda Brasil é muito mais de que um programa de mobilização. É um ‘sentimento' participativo cotidiano que deve habitar cada cidadão." (Folder do Boletim Acorda Brasil, ano 1, n. 1. 1997).

Recebido em: $\quad 22 / 12 / 11$

Aprovado em: $\quad$ 19/02/12 